\title{
ANALISIS PENGENDALIAN KUALITAS PRODUK MENGGUNAKAN PENDEKATAN STATISTICAL QUALITY CONTROL (SQC) DI PT. SAMCON
}

\author{
Alfie Oktavia ${ }^{1)}$, Dene Herwanto ${ }^{2)}$ \\ ${ }^{1,2)}$ Prodi Teknik Industri, Fakultas Teknik, Universitas Singaperbangsa Karawang \\ Email : alfieokta1920@gmail.com
}

\begin{abstract}
Abstrak, PT. Samcon adalah perusahaan yang memproduksi kapasitor yang kegiatan produksinya terbagi menjadi beberapa proses, dimana masing-masing proses dikerjakan oleh departemen yang berbeda. Penelitian ini dilakukan dengan tujuan untuk mengetahui tingkat kerusakan, mengidentifikasi faktor-faktor penyebab kerusakan serta merekomendasikan tindakan perbaikan. Metode yang digunakan yaitu metode Statistical Quality Control (SQC) yang dilakukan dengan alat bantu statistik diantaranya: checksheet, histogram, diagram pareto, peta kendali dan fishbone diagram. Hasil penelitian menunjukkan bahwa kerusakan produk terbanyak terjadi di departemen coating dan didominasi oleh tiga jenis kerusakan yaitu coating NG $(59,71 \%)$, popo $(11,71 \%)$ dan doriogiri $(10,43 \%)$, hasil analisis peta kendali untuk jumlah total keluar sebesar $46,7 \%$. Tindakan yang dilakukan untuk meminimalkan kerusakan yaitu dengan mengadakan training and education untuk operator, membuat cooling zone, memeriksa penyangga deji sebelum digunakan, membersihkan heater dan pully secara berkala, melakukan perawatan dan pemeriksaan bearing, menambah fasilitas pendingin ruangan, mengganti wheel, memeriksa powder sebelum digunakan, dan mengganti sensor pengisian powder dengan sistem timer.
\end{abstract}

Kata kunci : Pengendalian Kualitas, Statistical Quality Control, Alat Bantu Statistik

\section{PENDAHULUAN}

Persaingan dalam dunia industri semakin tinggi meskipun berada dalam kondisi keuangan yang tidak sehat. Hal ini mendorong pelaku usaha untuk menghasilkan barang atau jasa yang memiliki kualitas tinggi. Dengan kualitas yang tinggi tersebut maka akan memberikan kepuasan kepada pelanggan atau konsumen. Selain itu, dengan pengendalian kualitas pelaku usaha mampu bertahan dalam persaingan dengan pelaku usaha yang lain (Jha dkk, 2013). Salah satu teknik yang cocok dan dapat diterapkan adalah melalui kegiatan pengendalian kualitas (Andrina dkk, 2018).

Masalah kualitas telah mendorong strategi dan metodologi umum suatu perusahaan untuk memiliki intensitas dan bersaing di seluruh dunia dengan barangbarang dari perusahaan yang berbeda. Kualitas adalah gambaran umum barang dan jasa dalam mempromosikan, merancang, merakit dan memelihara yang membuat barang dan jasa yang digunakan memenuhi asumsi pembeli (Uriyani, 2009). Dengan cara ini, orang dapat mengatakan bahwa kualitas terjadi karena siklus yang baik dan terkendali serta sesuai dengan kebutuhan pasar. Menurut Dale (2003), kualitas merupakan sesuatu yang tidak bisa ditawar karena pesanan, kontrak maupun pelanggan yang hilang atas dasar ketidaksesuaian kualitas produk dan/atau layanan jauh lebih sulit untuk diperoleh kembali daripada kehilangan pesanan, kontrak ataupun pelanggan yang disebabkan oleh harga atau syarat pengiriman.

Pengendalian kualitas statistik atau statistical quality control adalah salah satu upaya pengendalian kualitas dengan menggunakan pendekatan statistik (Yuliasih dkk., 2014). Alasan utama dari penggunaan pengendalian kualitas statistik adalah untuk mengenali penyebab eksplisit dalam varietas atau kesalahan siklus melalui penyelidikan informasi (Ariani dkk, 2004). Dengan demikian, pengendalian kualitas statistik dapat diuraikan sebagai instrumen yang sangat membantu dalam membuat item sesuai penentuan dari awal siklus hingga akhir siklus (Elmas, 2017). Pada penelitian yang dilakukan oleh Meldayanoor dkk. (2018), pengumpulan data dilakukan dengan menggunakan checksheet, lalu dianalisis menggunakan diagram kendali untuk mengetahui apakah produk cacat masih berada dalam batas kendali atau tidak yang dilanjutkan dengan membuat diagram pareto agar dapat diketahui jenis cacat yang paling banyak terjadi yang kemudian akan 
ditelusuri penyebabnya menggunakan fishbone diagram atau diagram tulang ikan.

PT. Samcon merupakan perusahaan yang tergabung ke dalam SAMWHA Group Company yang berlokasi di Jalan Raya Subang Kp. Kiara Dua RT/RW 002/001, Cikumpay, Kecamatan Campaka, Kabupaten Purwakarta, Jawa Barat. Perusahaan ini memproduksi kapasitor untuk kemudian dikirimkan kepada para pelanggan di beberapa negara. Dalam hal ini, dapat dilihat bahwa PT. Samcon sudah memiliki pasar yang luas sehingga sistem pengendalian kualitas sangat perlu diterapkan dengan baik agar produk yang dihasilkan dapat memuaskan pelanggan. Dengan melakukan pengawasan terhadap kualitas suatu item maka kepercayaan dan kepuasan pelanggan akan bertahan atau bahkan meningkat.

Kegiatan produksi pada PT. Samcon terbagi menjadi beberapa proses, dimana masing-masing proses dikerjakan oleh departemen yang berbeda. Pada setiap proses produksi, pemeriksaan terhadap produk dilakukan pengecekan oleh operator produksi di masing-masing departemen. Selama proses produksi masih ditemukan banyak produk yang mengalami kecacatan yang pada akhirnya akan dibuang atau dilakukan pengerjaan ulang. Sering kali perusahaan harus melakukan pengerjaan ulang terhadap produk yang cacat dikarenakan jumlah produk cacat yang cukup banyak, namun hal tersebut tentu akan menghabiskan cukup banyak biaya dan tenaga. Oleh karena itu, diperlukan pengendalian kualitas yang baik agar dapat meminimalisir terjadinya produk cacat.

Tingkat cacat produk pada PT. Samcon memang masih sesuai dengan yang diharapkan atau dengan kata lain masih sesuai dengan target yang ditetapkan perusahaan, namun jika dilihat tingkat kecacatan setiap bulannya, masih terdapat tingkat cacat produk yang berfluktuasi cukup jauh. Berdasarkan fenomena tersebut, perlu dilakukan penelitian untuk menganalisis pengendalian kualitas di PT. Samcon dengan menggunakan pendekatan SQC.

SQC adalah kerangka berpikir yang dibuat dalam rangka menjaga standar kualitas item dengan biaya yang minimum melalui pendekatan statistik. Untuk menentukan pilihan di SQC dapat digunakan suatu instrumen yang disebut seven tools.

Penelitian ini bertujuan untuk mengetahui apakah siklus produksi pada PT. Samcon masih dapat dikatakan terkendali atau tidak dan mengetahui penyebab terjadinya produk cacat. Penelitian ini diharapkan dapat menjadi sesuatu yang berguna bagi PT. Samcon sebagai bahan pemikiran yang dinamis.

\section{METODE}

Penelitian ini dilakukan menggunakan metode SQC, dengan 5 tahapan yang dilakukan, yaitu: (1) tahap pemeriksaan dengan menggunakan checksheet, (2) analisis dengan histogram, (3) analisis dengan diagram pareto, (4) analisis dengan peta kendali, dan (5) analisis fishbone diagram. Jenis kerusakan yang dominan dikelompokkan dalam tabel untuk direncanakan tindakan perbaikan.

\section{Checksheet}

Checksheet merupakan instrumen yang digunakan sebagai lembar pencatatan informasi yang sederhana dan lugas, sehingga meminimalkan kemungkinan terjadinya kesalahan saat dilakukan proses pengumpulan informasi (Rani \& Setiawan, 2016). Alasan penggunaan lembar periksa ini adalah untuk mempermudah proses pengumpulan dan analisis informasi dan mengetahui titik-titik masalah dengan cara menghitung frekuensi munculnya jenis cacat produk yang berkaitan dengan kualitasnya. Informasi tersebut bermanfaat dalam memutuskan pilihan untuk melakukan perbaikan atau tidak.

2. Histogram

Histogram merupakan diagram batang yang berfungsi untuk menunjukkan penyebaran informasi dan data berulang sehingga dapat diketahui seberapa sering setiap nilai yang berbeda dalam indeks informasi terjadi (Ulkhaq dkk., 2017). Alasan penggunaan histogram adalah untuk menunjukkan data secara grafis untuk melihat pola pada setiap komponen sehingga lebih mudah untuk dianalisis (Diniaty \& Sandi, 2016).

3. Diagram pareto

Diagram pareto atau pareto analysis adalah diagram balok dan diagram baris yang menunjukkan proporsi setiap jenis informasi secara keseluruhan. Pada diagram pareto, kategori kejadian diatur berdasarkan ukuran, dari yang terbesar hingga ke yang terkecil di sebelah kanan. Urutan tersebut menunjukkan urutan prioritas (Rusdianto dkk., 2011). Diagram pareto digunakan untuk menentukan cacat produk yang dominan dengan mengklasifikasikan cacat 
produk dan menentukan tingkat kecacatan dari yang terbesar sampai yang terkecil (Meldayanoor dkk., 2018).

4. Peta kendali $p$

Peta kendali atau peta kontrol adalah instrumen yang secara grafis digunakan untuk memutuskan kerusakan yang dialami masih dapat dikategorikan masuk akal atau tidak masuk akal (Hairiyah dkk., 2020). Dari peta kontrol ini dapat diketahui perubahan informasi pada kurun waktu tertentu, namun peta ini tidak menunjukkan alasan penyimpangan meskipun faktanya penyimpangan tersebut akan terlihat pada peta kontrol. Sedangkan peta kendali kerusakan ( $\mathrm{p}$ chart), berfungsi dalam menganalisis jumlah item yang mengalami kerusakan yang ditemukan pada pemeriksaan terhadap total barang yang diperiksa. Adapun langkah-langkah dalam membuat peta kendali menurut Sulastri (2018) adalah:

a. Menghitung proporsi kecacatan

$$
p=\frac{n p}{n}
$$

dimana:

$n p$ : jumlah cacat dalam subgroup

$n$ : jumlah yang diinspeksi dalam subgroup

b. Menghitung Center Line (CL)

$$
C L=\bar{p}=\frac{\sum n p}{\sum n}
$$

dimana:

$\sum n p:$ akumulasi/total cacat produk

$\sum n$ : total yang diperiksa

c. Menghitung batas kontrol atas atau Upper Control Limit (UCL), yaitu garis batas maksimal untuk suatu penyimpangan yang masih diperbolehkan.

$$
U C L=\bar{p}+3 \sqrt{\frac{\bar{p}(1-\bar{p})}{n}}
$$

dimana:

$\bar{p}$ : rata-rata cacat produk

$n$ : jumlah produksi

d. Menghitung batas kontrol bawah atau Lower Control Limit (LCL), yaitu garis batas minimum untuk suatu penyimpangan yang masih diperbolehkan. Nilai atau proporsi batas kontrol bawah atau LCL selalu bernilai positif, jika ditemukan nilai negatif dalam perhitungan LCL maka LCL ditetapkan sama dengan nol (Rahayu \& Supono, 2020).

$$
U C L=\bar{p}-3 \sqrt{\frac{\bar{p}(1-\bar{p})}{n}}
$$

dimana:

$\bar{p}$ : rata-rata cacat produk

$n$ : jumlah produksi

\section{Fishbone diagram}

Fishbone diagram dikenal sebagai cause and effect diagram atau diagram Ishikawa (Panjaitan dkk., 2019). Cause and effect diagram adalah garis-garis yang menunjukkan garis elemen dari penyebab terjadinya cacat produk yang dikenali dari berbagai aspek, diantaranya: manusia, mesin, metode, material, dan lingkungan (Vikri, 2018).

\section{HASIL DAN PEMBAHASAN}

\section{Checksheet Produk Cacat}

Tahap awal dalam melakukan kontrol kualitas dengan pendekatan SQC yaitu membuat lembar periksa (checksheet). Sebagai catatan bahwa pemeriksaan terhadap produk dilakukan pada setiap departemen yang terlibat dalam kegiatan produksi. Dalam hal ini, terdapat 4 departemen yang menghasilkan cacat produk dengan jenis yang berbeda. Hasil dari pengumpulan informasi menggunakan checksheet tertera pada Tabel 1.

Tabel 1. Checksheet Produk Cacat di PT. Samcon

\begin{tabular}{|l|l|c|c|c|c|}
\hline \multicolumn{2}{|c|}{ Periode } & \multicolumn{4}{c|}{ Departemen } \\
\cline { 3 - 6 } \multicolumn{2}{|c|}{} & Endo & Jorip & Coating & Gheumsa \\
\hline \multirow{3}{*}{2020} & Januari & 43.751 & 55.541 & 317.546 & 78.093 \\
\cline { 2 - 6 } & Februari & 55.409 & 36.600 & 320.723 & 66.694 \\
\cline { 2 - 6 } & Maret & 146.902 & 111.360 & 295.300 & 191.530 \\
\cline { 2 - 6 } & April & 102.739 & 81.241 & 260.369 & 182.834 \\
\cline { 2 - 6 } & Mei & 46.429 & 27.423 & 260.145 & 64.192 \\
\hline
\end{tabular}




\begin{tabular}{|c|l|c|c|c|c|}
\hline & Juni & 71.021 & 71.065 & 322.371 & 101.608 \\
\cline { 2 - 6 } & Juli & 49.643 & 73.966 & 211.094 & 162.557 \\
\cline { 2 - 6 } & Agustus & 78.638 & 83.204 & 208.665 & 144.966 \\
\cline { 2 - 6 } & September & 97.566 & 112.731 & 176.751 & 127.888 \\
\cline { 2 - 6 } & Oktober & 87.494 & 98.726 & 289.363 & 149.881 \\
\cline { 2 - 6 } & November & 31.826 & 120.927 & 352.860 & 160.142 \\
\cline { 2 - 6 } & Desember & 41.475 & 165.213 & 353.661 & 243.203 \\
\hline \multirow{3}{*}{2021} & Januari & 48.764 & 152.926 & 287.557 & 249.385 \\
\cline { 2 - 6 } & Februari & 40.385 & 143.249 & 378.059 & 215.721 \\
\cline { 2 - 6 } & Maret & 58.801 & 189.360 & 437.958 & 292.469 \\
\hline \multicolumn{2}{|l|}{ Total } & 1.000 .883 & 1.523 .592 & 4.472 .692 & 2.431 .163 \\
\hline
\end{tabular}

Sumber: PT. Samcon (2021)

Tabel 1 menunjukkan bahwa departemen yang menghasilkan produk cacat terbanyak yaitu departemen coating, maka pembahasan berikutnya berfokus pada jenis cacat produk yang dihasilkan oleh departemen coating. Adapun rincian jenis dan jumlah cacat atau deffect produk yang dihasilkan oleh departemen coating terdapat pada Tabel 2. Quantity input pada Tabel 2 menunjukkan jumlah barang yang diterima atau diproses oleh departemen coating selama periode Januari 2020 sampai Maret 2021.

Tabel 2. Deffect Departemen Coating

\begin{tabular}{|l|c|c|}
\hline Jenis Cacat & Quantity Input & $\begin{array}{c}\text { Jumlah } \\
\text { Cacat }\end{array}$ \\
\hline Coating NG & 1.139 .601 .524 & 2.670 .838 \\
\hline Popo & 1.139 .601 .524 & 499.813 \\
\hline Doriogiri & 1.139 .601 .524 & 466.498 \\
\hline Marking & 1.139 .601 .524 & 392.944 \\
\hline Mitnochul & 1.139 .601 .524 & 149.569 \\
\hline $\begin{array}{l}\text { Coating } \\
\text { berserabut }\end{array}$ & 1.139 .601 .524 & 72.258 \\
\hline Imurjel & 1.139 .601 .524 & 62.588 \\
\hline $\begin{array}{l}\text { Coating } \\
\text { kotor }\end{array}$ & 1.139 .601 .524 & 61.331 \\
\hline Gigong & 1.139 .601 .524 & 40.723 \\
\hline MU Marking & 1.139 .601 .524 & 25.969 \\
\hline Gipo & 1.139 .601 .524 & 18.766 \\
\hline $\begin{array}{l}\text { Coating } \\
\text { menonjol }\end{array}$ & 1.139 .601 .524 & 11.395 \\
\hline \multicolumn{2}{|c|}{ Total } & 4.472 .692 \\
\hline
\end{tabular}

\section{Histogram Produk Cacat}

Setelah membuat checksheet, langkah selanjutnya yaitu membuat histogram. Histogram disajikan dalam bentuk diagram batang sehingga mempermudah dalam melihat jumlah item yang cacat.

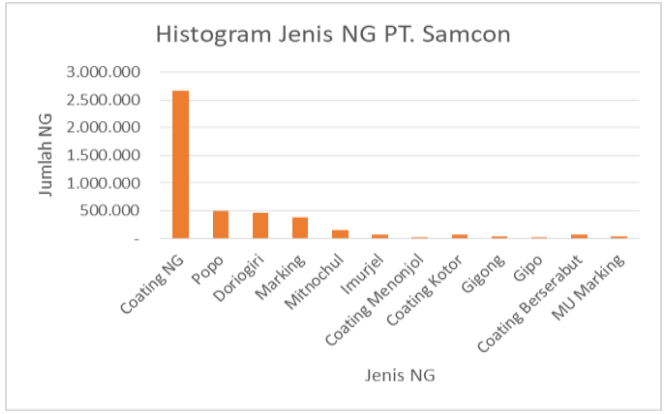

Gambar 1. Histogram Produk Cacat

\section{Peta Kendali Produk Cacat}

Dalam pengujian ini peta kendali $p$ digunakan karena jumlah pengujian (ukuran pengujian) yang dikumpulkan tidak tetap. Peta kendali $\mathrm{p}$ memiliki fungsi mengukur sejauh mana ketidaksesuaian atau deformitas yang terjadi. Setelah dilakukan perhitungan sesuai dengan persamaan (1), (2), (3), dan (4) maka dihasilkan peta kendali seperti ditunjukkan pada Gambar 2.

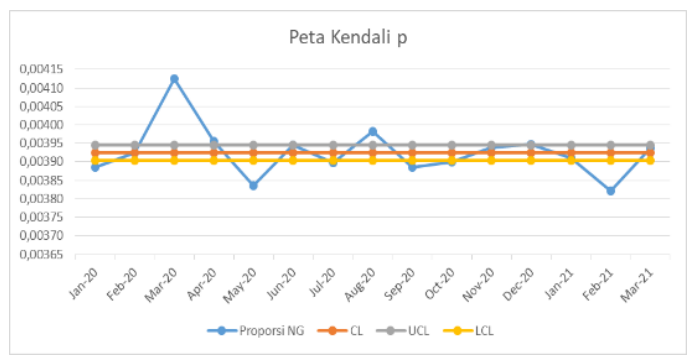

Gambar 2. Peta Kendali Cacat Produk

Setelah diteliti menggunakan peta kendali $p$, terlihat bahwa terdapat beberapa data yang berada di luar batas kendali (terjadi penyimpangan), lebih tepatnya terdapat 7 titik yang menyimpang. Hal tersebut menunjukkan bahwa masih terdapat proses produksi yang tidak terkendali, 
sehingga diperlukan adanya perbaikan dalam rangka perbaikan kualitas.

\section{Diagram Pareto Produk Cacat}

Diagram pareto digunakan untuk mengetahui jenis kecacatan yang paling dominan pada hasil produksi selama bulan Januari 2020 hingga bulan Maret 2021. Langkah awal dalam membuat diagram pareto yaitu mengurutkan jenis cacat yang memiliki tingkat tertinggi hingga terendah dan menghitung persentase cacat dan persentase kumulatif dari setiap jenis cacat seperti yang terdapat pada Tabel 3 .

Berdasarkan data pada Tabel 3 tersebut, dapat dibuat diagram pareto seperti ditunjukkan pada Gambar 3.

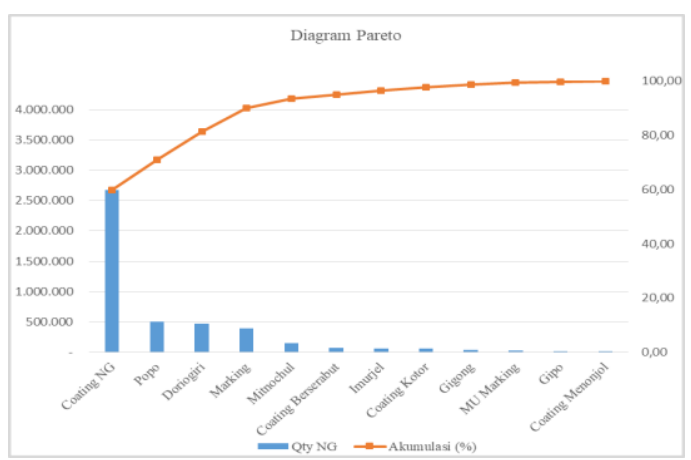

Gambar 3. Diagram Pareto Produk Cacat
Berdasarkan hasil pengolahan data diketahui bahwa sekitar $80 \%$ kecacatan produk selama proses produksi di PT. Samcon pada bulan Januari 2020 hingga Maret 2021 didominasi oleh 3 penyebab yaitu coating $\mathrm{NG}$ dengan persentase sebesar $59,71 \%$, popo sebesar $11,71 \%$ dan doriogiri sebesar $10,43 \%$. Dengan demikian, dapat disimpulkan bahwa jenis cacat paling dominan adalah coating NG.

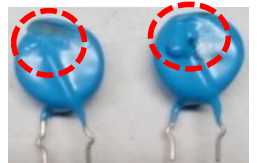

(a) Coating NG

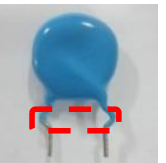

(b) Popo

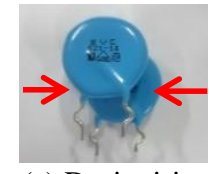

(c) Doriogiri
Gambar 4. Jenis-jenis cacat produk Sumber: PT. Samcon (2021)

Tabel 3. Persentase Deffect

\begin{tabular}{|l|c|c|c|}
\hline \multicolumn{1}{|c|}{ Jenis Cacat } & Jumlah Cacat & Persentase Cacat (\%) & Persentase Kumulatif (\%) \\
\hline Coating NG & 2.670 .838 & 59,71 & 59,71 \\
\hline Popo & 499.813 & 11,17 & 70,89 \\
\hline Doriogiri & 466.498 & 10,43 & 81,32 \\
\hline Marking & 392.944 & 8,79 & 90,10 \\
\hline Mitnochul & 149.569 & 3,34 & 93,45 \\
\hline Coating berserabut & 72.258 & 1,62 & 95,06 \\
\hline Imurjel & 62.588 & 1,40 & 96,46 \\
\hline Coating kotor & 61.331 & 1,37 & 97,83 \\
\hline Gigong & 40.723 & 0,91 & 98,75 \\
\hline MU Marking & 25.969 & 0,58 & 99,33 \\
\hline Gipo & 18.766 & 0,42 & 99,75 \\
\hline Coating menonjol & 11.395 & 0,25 & 100 \\
\hline Total & 4.472 .692 & 100 & \\
\hline
\end{tabular}

\section{Fishbone Diagram Produk Cacat}

Setelah mengetahui jenis NG yang terjadi, maka pada saat itu penting bagi PT. Samcon membuat langkah perbaikan agar dapat meminimalisir terjadinya kerusakan yang serupa. Cara yang ditempuh harus sesuai dengan permasalahan yang ada, sehingga penting untuk mengetahui terlebih 
dahulu unsur-unsur yang menjadi penyebab terjadinya produk NG. Instrumen dapat digunakan untuk mencari penyebab terjadinya produk $\mathrm{NG}$ yaitu fishbone diagram. Gambar 4 hingga Gambar 6 menunjukkan fishbone chart masingmasing jenis cacat.

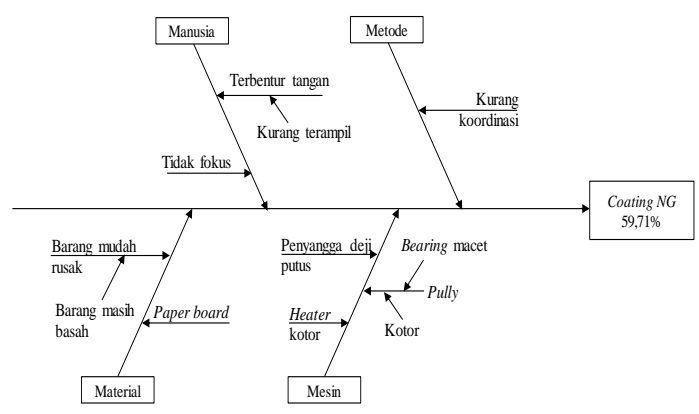

Gambar 5. Fishbone Diagram Coating

Faktor yang menyebabkan terjadinya coating NG dapat dilihat pada Gambar 4. Berdasarkan penelitian dan wawancara yang dilakukan, menunjukkan bahwa faktor potensial yang menyebabkan coating NG adalah faktor metode, manusia, material, dan mesin. Namun faktor material memberikan pengaruh lebih besar pada coating NG dibandingkan dengan faktor metode, manusia dan mesin.



Gambar 6. Fishbone Diagram Popo

Faktor yang menyebabkan terjadinya popo dapat dilihat pada Gambar 5. Berdasarkan pengamatan dan wawancara yang dilakukan, diketahui bahwa faktor potensial yang menyebabkan popo adalah faktor metode, manusia, lingkungan, dan mesin. Namun faktor mesin memberikan pengaruh lebih besar pada popo dibandingkan dengan faktor lainnya.

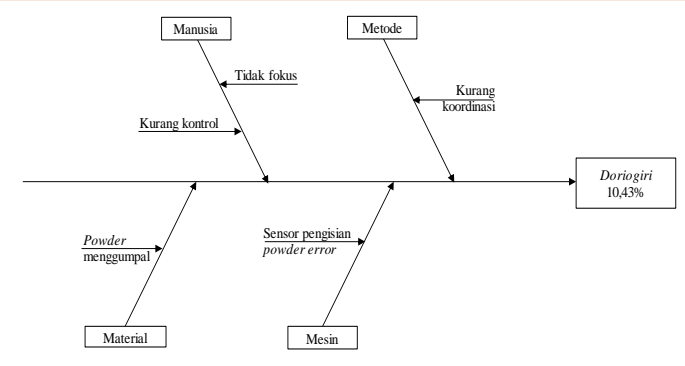

Gambar 7. Fishbone Diagram Doriogiri

Faktor yang menyebabkan terjadinya doriogiri dapat dilihat pada Gambar 6 . Berdasarkan pengamatan dan interview yang dilakukan, diketahui bahwa faktor potensial yang menyebabkan doriogiri adalah faktor metode, manusia, material, dan mesin. Namun faktor mesin memberikan pengaruh lebih besar pada popo dibandingkan dengan faktor lainnya.

\section{Rencana Perbaikan}

Setelah mengetahui penyebab atau faktor-faktor yang menyebabkan terjadinya cacat produk, maka langkah selanjutnya yaitu membuat rencana perbaikan agar jumlah produk cacat dapat diminimalkan. Berikut merupakan rencana perbaikan yang diusulkan.

Tabel 4. Rekomendasi Perbaikan

\begin{tabular}{|l|l|}
\hline Jenis Cacat & \multicolumn{1}{|c|}{ Tindakan } \\
\hline Coating & $\begin{array}{l}\text { Membuat cooling zone } \\
\text { agar barang kering } \\
\text { sebelum keluar dari mesin. }\end{array}$ \\
\hline Popo & $\begin{array}{l}\text { Mengganti wheel dengan } \\
\text { yang rata melakukan } \\
\text { perbaikan dan perawatan } \\
\text { secara rutin. }\end{array}$ \\
\hline Doriogiri & $\begin{array}{l}\text { Melakukan pemeriksaan } \\
\text { terhadap powder sebelum } \\
\text { digunakan, mengganti } \\
\text { sensor pengisian powder } \\
\text { dengan sistem timer. }\end{array}$ \\
\hline
\end{tabular}

\section{KESIMPULAN DAN SARAN}

\section{Kesimpulan}

Berdasarkan penelitian yang telah dilakukan, didapatkan beberapa kesimpulan sebagai berikut:

a) Tingkat kerusakan atau cacat produk pada PT. Samcon berbeda-beda untuk setiap departemen. Departemen dengan tingkat 
kerusakan atau cacat produk tertinggi yaitu departemen coating. Adapun jenis NG yang terjadi di departemen coating diantaranya yaitu coating NG, popo, doriogiri, marking, mitnochul, imurjel, coating menonjol, coating kotor, gigong, gipo dan coating berserabut. Setelah dilakukan analisis, diketahui bahwa jenis NG yang paling dominan yaitu coating NG dengan persentase sebesar $59,71 \%$, popo dengan persentase sebesar $11,17 \%$ dan doriogiri dengan persentase sebesar $10,43 \%$.

b) Faktor penyebab cacat atau deformitas produk dalam kegiatan produksi meliputi faktor manusia (man), faktor metode (method), faktor mesin (machine), faktor material (material) dan faktor lingkungan (environment). Penyebab utama terjadinya coating NG adalah karena faktor material yaitu barang yang mudah rusak karena masih dalam keadaan basah. Penyebab utama terjadinya popo adalah karena faktor mesin yaitu wheel yang tidak rata dan putaran winder wheel tidak stabil begitu juga dengan faktor utama penyebab terjadinya doriogiri adalah faktor mesin yaitu sensor pengisian powder yang error.

c) Usulan tindakan perbaikan untuk mengatasi jenis kerusakan coating NG adalah dengan membuat cooling zone sehingga barang sudah kering sebelum keluar dari mesin. Usulan tindakan perbaikan untuk mengatasi jenis kerusakan popo yaitu dengan melakukan membuat jadwal perawatan wheel dan winder wheel, sedangkan usulan tindakan perbaikan untuk mengatasi jenis kerusakan doriogiri yaitu dengan melakukan pemeriksaan terhadap powder sebelum digunakan dan mengganti sensor pengisian powder menjadi sistem timer.

\section{Saran}

Adapun beberapa saran yang diajukan untuk perusahaan diantaranya:

1. Perusahaan perlu menggunakan metode statistik untuk menemukan jenis cacat produk yang sering terjadi dan penyebabnya sehingga dapat dengan cepat mengambil keputusan dalam pencegahan maupun penanggulangan untuk mengurangi tingkat kerusakan yang terjadi.

2. Berdasarkan penelitian yang telah dilakukan dengan menggunakan alat bantu statistik, perusahaan dapat memfokuskan pengendalian kualitas dengan melakukan tindakan perbaikan pada jenis kerusakan yang memiliki jumlah besar atau paling dominan dalam produksi.

\section{DAFTAR PUSTAKA}

Andrina, D. P., F. Rahmatika, dan M. Susanto. 2018. Upaya Sustainabilitas UKM Susu Melalui Pengendalian Kualitas Kandungan Kadar Lemak Susu Menggunakan Statistical Quality Control Method. Jurnal Inovatif, Vol. 8, No. 1, Hal. 1-8.

Dale, B. G. 2003. Managing Quality. 4th ed. Malden, MA: Blackwell Publishing Ltd.

Diniaty, D., dan Sandi. 2016. Analisis Kecacatan Produk Tiang Listrik Beton Menggunakan Metode Seven Tools dan New Seven Tools (Studi Kasus: PT. Kunango Jantan). Jurnal Teknik Industri, Vol. 2, No. 2, Hal. 155-162.

Elmas, M. S. H. 2017. Pengendalian Kualitas dengan Menggunakan Metode Statistical Quality Control (SQC) untuk Meminimumkan Produk Gagal pada Toko Roti Barokah Bakery. WIGA: Jurnal Penelitian Ilmu Ekonomi, Vol. 7, No. 1, Hal. 15-22.

Hairiyah, N., R. R. Amalia, dan Nuryati. 2020. Pengendalian Kulalitas Amplang Menggunakan Seven Tools di UD. Kelompok Melati. Agrointek, Vol. 14, No., Hal. 249-257.

Jha, M., R. K. Tyagi, dan G. Gupta. 2013. Reduction of Rejected Components in an Automobile Assembly Line Using Quality Tools. European Journal of Applied Engineering and Scientific Research, Vol. 2, No. 3, Hal. 13-17.

Meldayanoor, M., R. R. Amalia, dan M. Ramadhani. 2018. Analisis Statistical Quality Control (SQC) Sebagai Pengendalian dan Perbaikan Kualitas Produk Tortilla di UD. Noor Dina Group. Jurnal Teknologi Agro-Industri, Vol. 5, No. 2, Hal. 132-140.

Panjaitan, M. A., A. Suryantini, dan J. Jamhari. 2019. Quality Control of Raw Materials for Candied Carica Using P-Chart Analysis and Fishbone Diagram. JAM: Jurnal Aplikasi Manajemen, Vol. 17, No. 3, Hal. 416-425.

Rahayu, P., dan J. Supono. 2020. Analisis Pengendalian Kualitas Produk Menggunakan Metode Statistical Quality 
Control (SQC) di Plant D Divisi Curing PT. Gajah Tunggal, Tbk. Jurnal Teknik: Universitas Muhammadiyah Tangerang, Vol. 9, No. 1, Hal. 81-91.

Rani, A. M., dan W. Setiawan. 2016. Menganalisis Defect Sanding Mark Unit Pick Up TMC dengan Metode Seven Tools PT. ADM. JISI: Jurnal Integrasi Sistem Industri, Vol. 3, No. 1, Hal. 15-22.

Rusdianto, A. S., N. Novijanto, dan R. Alihsany. 2011. Penerapan Statistical Quality Control (SQC) pada Pengolahan Kopi Robusta Cara Semi Basah. Jurnal Agroteknologi, Vol. 5, No. 02, Hal. 1-10.

Sulastri. 2018. Analisis Pengendalian Kualitas (Quality Control) dalam Proses Produksi pada Home Industry Amplang Pipih Mahakam di Samarinda. eJurnal Administrasi Bisnis, Vol. 6, No. 4, Hal. 1583-1594.

Ulkhaq, M. M., S. N. W. Pramono, dan R. Halim. 2017. Aplikasi Seven Tools untuk
Mengurangi Cacat Produk pada Mesin Communite di PT. Masscom Graphy, Semarang. Jurnal PASTI, Vol. XI, No. 3, Hal. 220-230.

Uriyani, D. 2009. Pengendalian Kualitas Statistik pada Proses Produksi Percetakan Buku di CV. Aneka Ilmu Semarang. Skripsi. Program Studi Matematika, Universitas Negeri Semarang.

Vikri, M. Z. 2018. Penerapan Metode Statistical Quality Control (SQC) dalam Meminimalisir Cacat Produk Paving Block K300 - T6 di PT. ASE Gresik. Jurnal Pendidikan Teknik Mesin, Vol. 6, No. 03, Hal. 86-92.

Yuliasih, N. K., I. M. Nuridja, dan L. E. Tripalupi. 2014. Analisis Pengendalian Kualitas Produk pada Perusahaan Garmen Wana Sari Tahun 2013. Jurnal Pendidikan Ekonomi Undiksha, Vol.4, No. 1, Hal. 1-12. 